Supporting Information

\title{
Formate-Catalyzed Selective Reduction of Carbon Dioxide to Formate Products using Hydrosilanes
}

Ken Motokura, ${ }^{*}{ }^{a, b}$ Chihiro Nakagawa, ${ }^{a}$ Ria Ayu Pramudita, ${ }^{a}$ Yuichi Manaka ${ }^{a, c}$

a Department of Chemical Science and Engineering, School of Materials and Chemical Technology, Tokyo Institute of Technology, 4259 Nagatsuta-cho, Midori-ku, Yokohama, 226-8502, Japan

*e-mail: motokura.k.ab@m.titech.ac.jp

${ }^{b}$ PRESTO, Japan Science and Technology Agency (JST), Saitama 332-0012, Japan

${ }^{c}$ Renewable Energy Research Center, National Institute of Advanced Industrial Science and Technology, 2-2-9 Machiikedai, Koriyama, Fukushima 963-0298, Japan

\section{Contents}

$\begin{array}{ll}\text { General Methods } & \text { S2 }\end{array}$

$\begin{array}{ll}\text { Typical Procedure for preparation of TBA formate } & \text { S2 }\end{array}$

$\begin{array}{lr}\text { Typical Procedure for Hydrosilylation } & \text { S2 }\end{array}$

Typical Procedure for Reuse Experiment $\quad$ S3

$\begin{array}{lr}\text { FT-IR Measurement } & \text { S4 }\end{array}$

In-situ ${ }^{1} \mathrm{H}$ NMR Measurement $\quad$ S4

$\begin{array}{ll}\text { Product Characterization } & \text { S6 }\end{array}$

$\begin{array}{ll}\text { References } & \text { S12 }\end{array}$

\section{Supporting Information}

Total number of pages 12

Total number of figures 8 
General Methods. The ${ }^{1} \mathrm{H}$ and ${ }^{13} \mathrm{C}$ NMR spectra were recorded in $\mathrm{CDCl}_{3}$ using a Bruker AVANCE 400 spectrometer operating at 400 and 100.61 MHz, respectively. A Shimadzu QP2010 instrument equipped with a DB-1 column was used for the GC-MS analyses.

Unless otherwise noted, all the other materials were purchased from Wako Pure Chemicals, Tokyo Kasei Co., Kanto Kagaku Co., and Aldrich Inc., and Sigma-Aldrich (Merck). Triisopropylbenzene was used as the internal standard. Formate salts were used without any further pretreatment such as dehydration.

\section{Typical Procedure for preparation of tetrabutylammonium formate (TBA} formate). ${ }^{[1]}$ To a glass reactor, methonal solution of tetrabutylammonium hydroxide (4.0 mmol, $4.0 \mathrm{~mL})$ and formic acid $(4.0 \mathrm{mmol})$ were added under Ar atmosphere. The resulting reaction mixture was stirred vigorously at room temperature for $24 \mathrm{~h}$. Then, the solvent was removed by vacuum evaporation. The obtained products were confirmed by the comparison of their ${ }^{1} \mathrm{H}$ and ${ }^{13} \mathrm{C}$ NMR spectra with those of authentic data. ${ }^{[1]}$

Procedure for Hydrosilylation of $\mathrm{CO}_{2}$ with hydrosilane. To a glass reactor equipped with a $\mathrm{CO}_{2}$ balloon was added tetrabutylammonium formate $(0.10 \mathrm{mmol})$, hydrosilane (Si-H: $2.9 \mathrm{mmol})$, and solvent $(2 \mathrm{~mL})$. The resulting reaction mixture was stirred vigorously at $60{ }^{\circ} \mathrm{C}$. The products were confirmed by the comparison of their GC-MS spectra and ${ }^{1} \mathrm{H}$ NMR spectra with those of authentic data ${ }^{[2-5]}$ and our previous report. ${ }^{[6]}$ The conversion and yields were determined by the internal standard technique using a $\mathrm{CDCl}_{3}$ solution of the reaction mixture. Conversion and yield were calculated using ${ }^{1} \mathrm{H}$ NMR signal: for dimethylpehnylsilane, Si-H (4.4 ppm), formyl group of silyl formate $(8.1 \mathrm{ppm})$ and formic acid $(8.0 \mathrm{ppm})$. For details of product spectra, see attached NMR 
chart at product characterization (page S6-S11) section. Triisopropylbenzene was used as the internal standard.

Typical Procedure for Reuse Experiment: To a glass reactor equipped with a $\mathrm{CO}_{2}$ balloon was added tetrabutylammonium formate $(0.10 \mathrm{mmol})$, triethoxysilane $(2.9 \mathrm{mmol})$, and toluene $(2 \mathrm{~mL})$. The resulting reaction mixture was stirred vigorously at $60{ }^{\circ} \mathrm{C}$ for 24 h. After the measurement of formate yield and conversion of silane, the reaction mixture was cooled to room temperature. Then, the colorless supernatant and pale yellow solid phase was separated. The separated solid was dissolved in $\mathrm{CDCl}_{3}$, and ${ }^{1} \mathrm{H} \mathrm{NMR}$ analysis of the solution indicates the presence of TBA formate (Figure S1(A)). ${ }^{1} \mathrm{H}$ NMR measurement of the supernatant implies no signals assigned to TBA formate in the toluene solution, as shown in Figure S1(B). New toluene solvent (2 mL) and triethoxysilane (2.9 mmol) were added to the separated solid, then the recycle reaction was conducted at 60 ${ }^{\circ} \mathrm{C}$ for $24 \mathrm{~h}$.

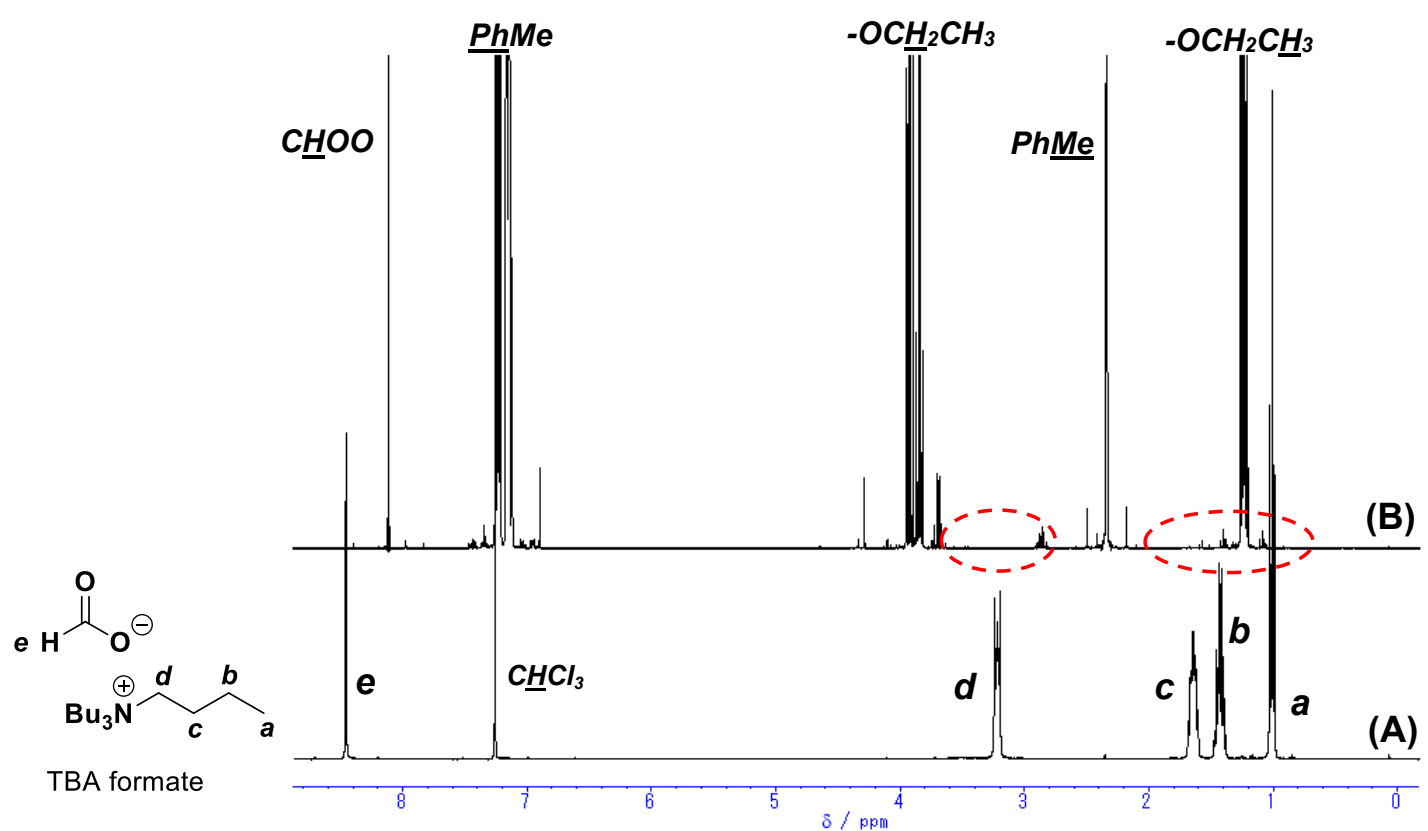

Figure S1. ${ }^{1} \mathrm{H}$ NMR spectra for $\mathrm{CDCl}_{3}$ solution of (A) pale yellow solid phase and (B) colorless supernatant after the reaction of triethoxysilane and $\mathrm{CO}_{2}$ using toluene solvent. 
FT-IR Measurement: FT-IR spectra were recorded from $4000-400 \mathrm{~cm}^{-1}$, using a Shimadzu IR Tracer-100 spectrometer with TGS detector. Each spectrum was the average of 45 scans using a spectral resolution of $2 \mathrm{~cm}^{-1}$. Spectra of neat dimethylphenylsilane, solvent, and solution of dimethylhydrosilane were measured using $\mathrm{KBr}$ crystal.

In-situ ${ }^{1}$ H NMR Measurement: To a NMR tube, DMSO- $d_{6}$ solution of TBA formate were added under Ar atmosphere. After ${ }^{1} \mathrm{H}$ NMR measurement at room temperature, dimethylphenylsilane was added to the solution, then the NMR scan was conducted.

After the scan, $\mathrm{CO}_{2}$ gas was introduced into the solution by bubbling at room temperature, then, the reaction was monitored by ${ }^{1} \mathrm{H}$ NMR. The signals assigned to TBA formate was shifted to upfiled as shown in Figure S2(A). Relative peak area of the formate ( $~ 8 \mathrm{ppm})$ increased with decrease of the area of $\mathrm{Si}-\mathrm{H}(4.4 \mathrm{ppm})$, as shown in Figure 2(B). GC-MS analysis of the reaction mixture indicates the formation of the corresponding silyl formate. These results imply that the hydrosilylation reaction proceeded. The peak shift of formate signal after addition of $\mathrm{CO}_{2}$ is due to rapid anion exchange between TBA formate and silyl formate. Reported rapid exchange reaction between silyl formate and TBA acetate is also support this reaction. ${ }^{[7]}$ 
(A)

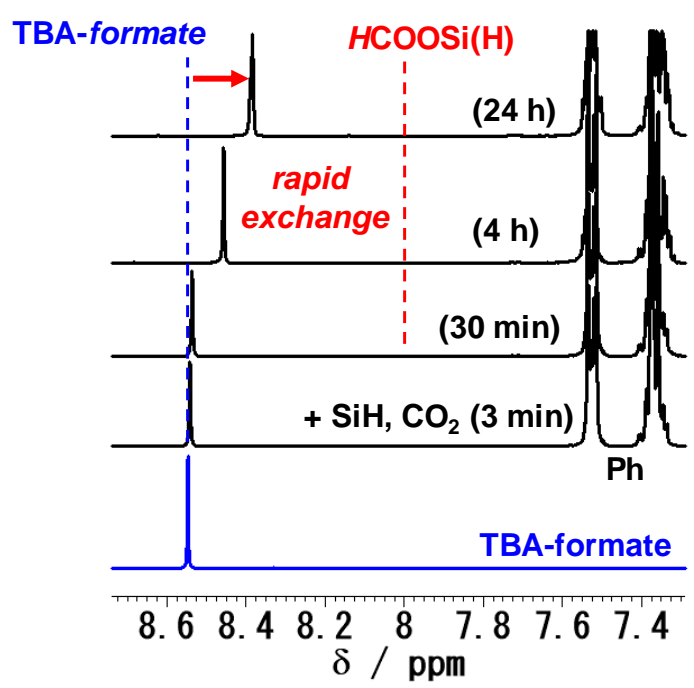

(B)

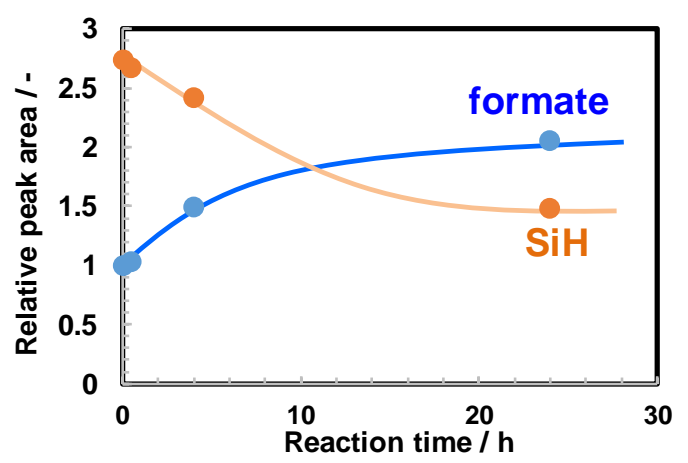

Figure S2. (A) In-situ ${ }^{1} \mathrm{H}$ NMR monitoring during hydrosilylation reaction and (B) relative peak area of formate group and $\mathrm{Si}-\mathrm{H}$ of hydrosilane during the reaction. 


\section{Product Characterization}<smiles>C[Si](C)(OC=O)c1ccccc1</smiles>

CAS Registry Number: 258267-32-2; Identification data.[2]

\section{${ }^{1}$ H NMR}
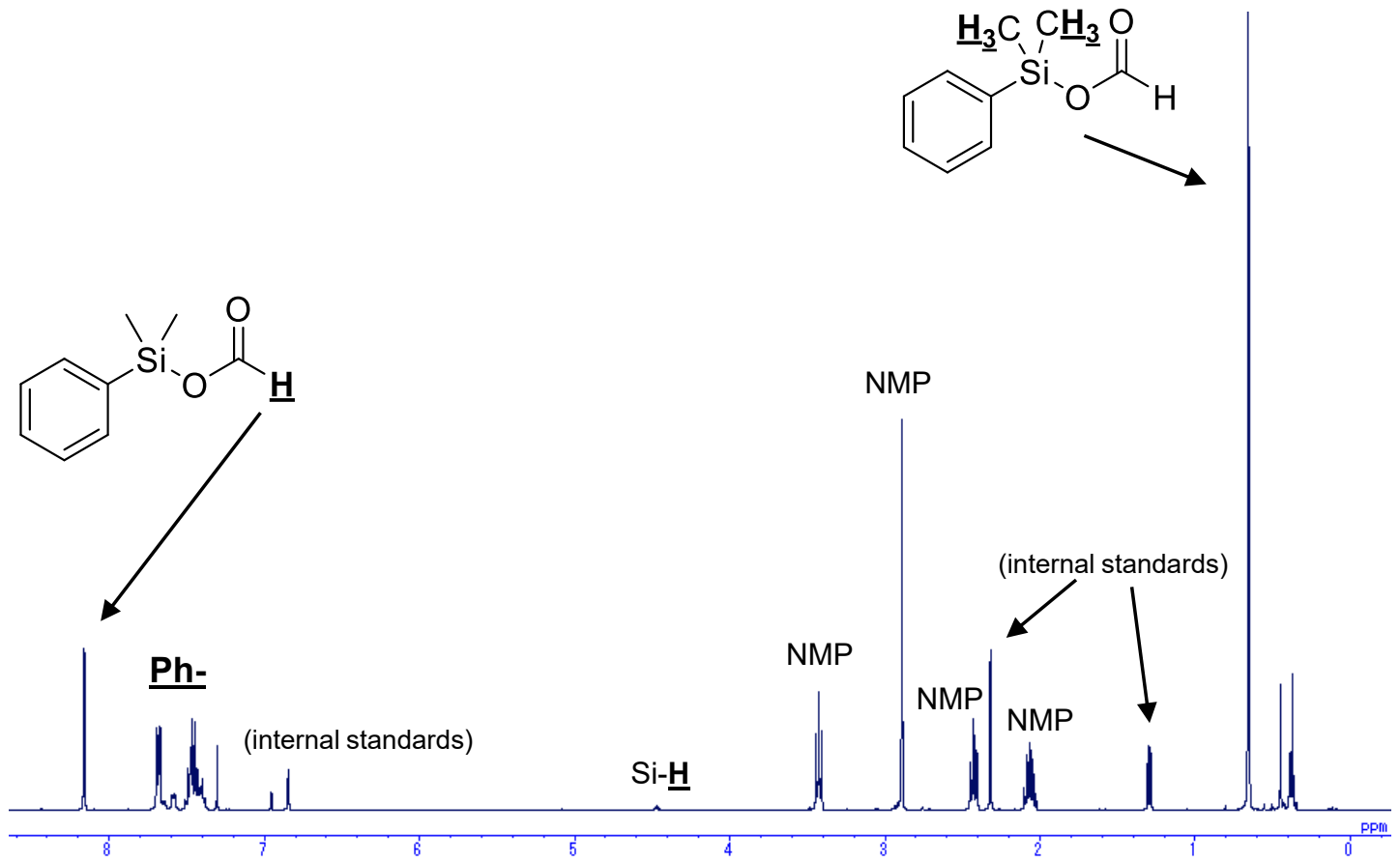

Internal standard: mesitylene and 1,3,5-triisopropylbenzene

\section{GC-MS}

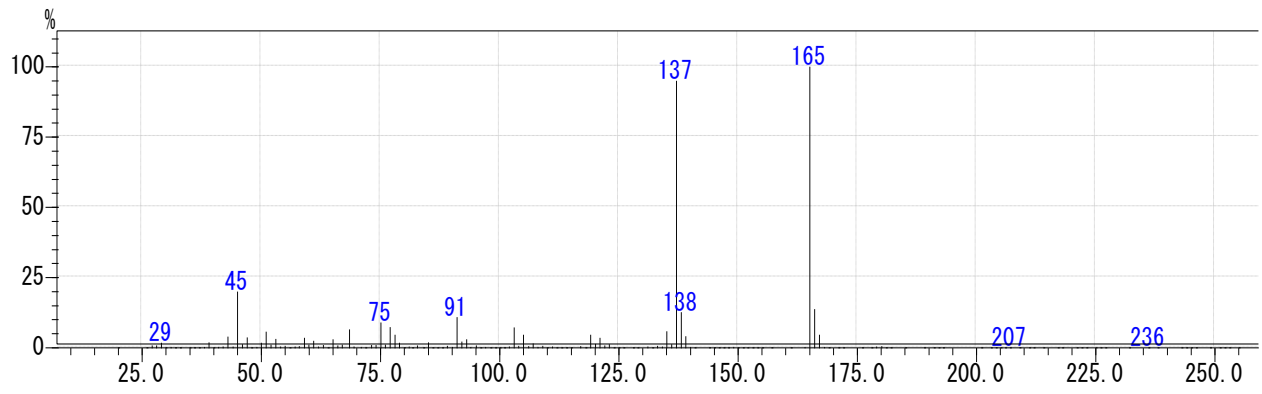

Figure S3. ${ }^{1} \mathrm{H}$ NMR and GC-MS data of product in Table 3, entry 1 
$\Gamma \mathrm{Si}_{\mathrm{O}} \stackrel{\mathrm{H}}{\mathrm{H}}_{\mathrm{H}}$

CAS Registry Number: 18296-01-0. Identification data.[3]

\section{${ }^{1}$ H NNR}

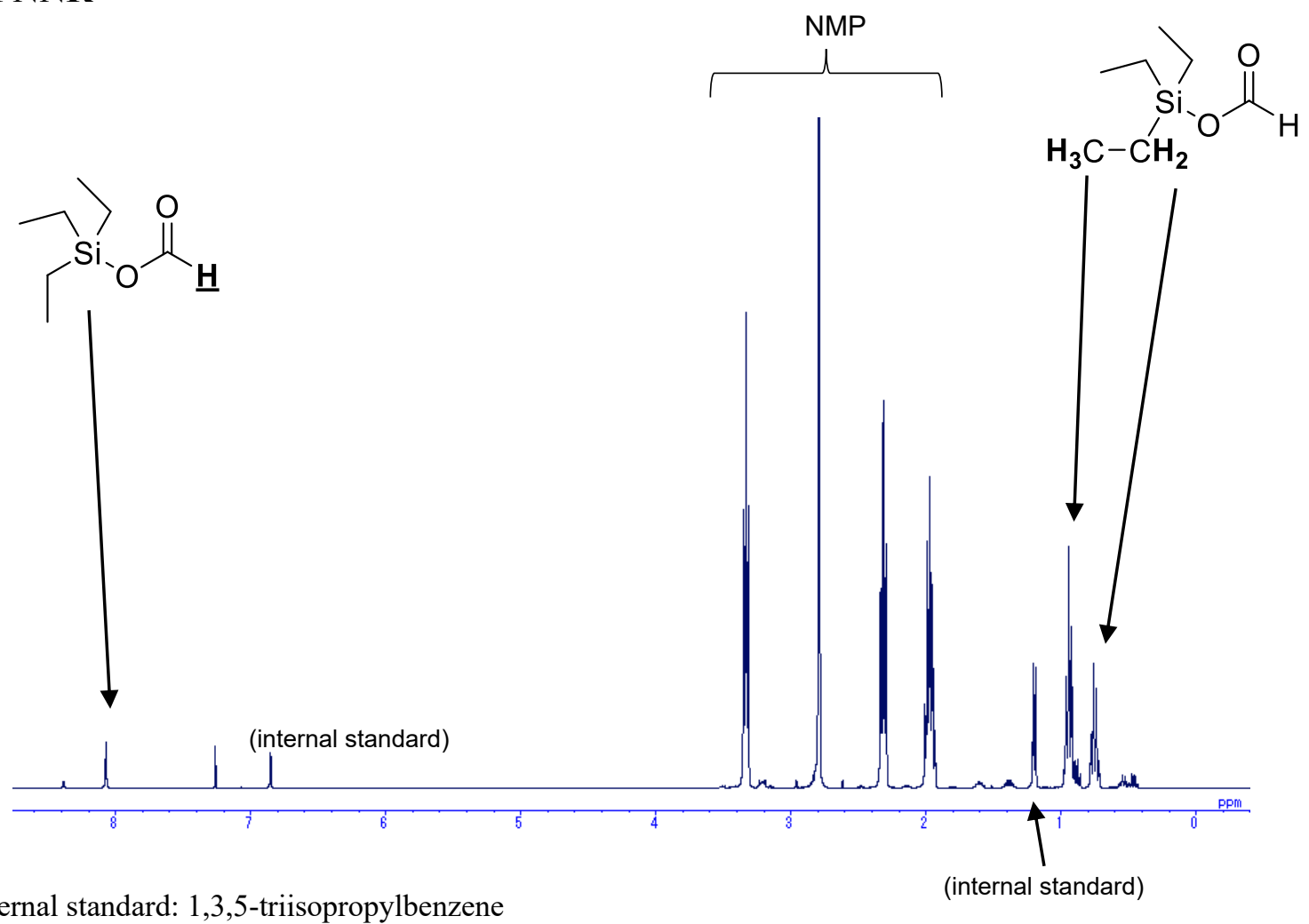

GC-MS

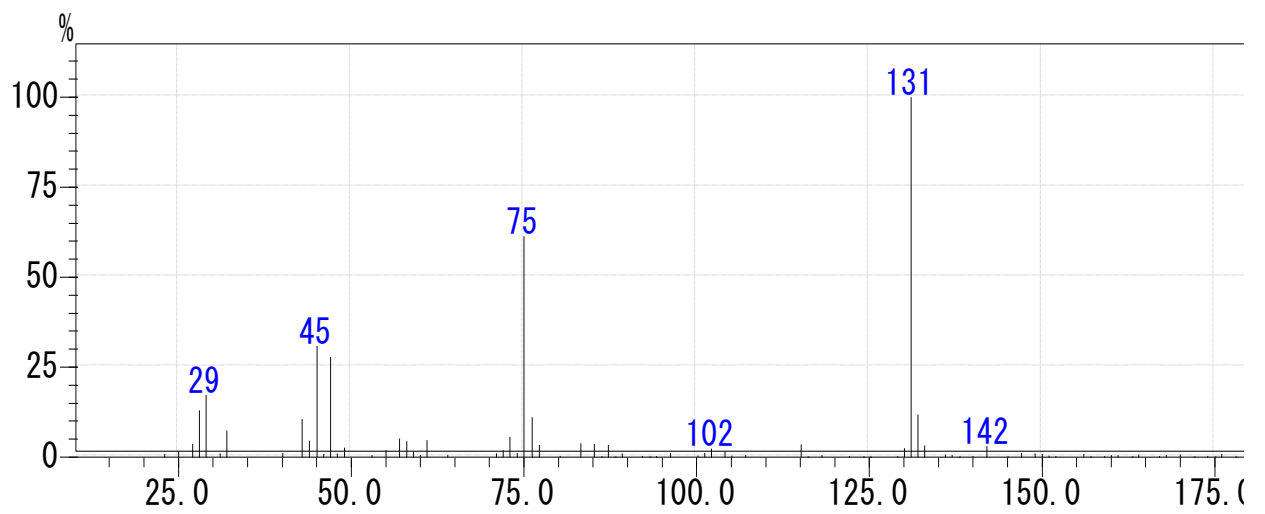

Figure S4. ${ }^{1} \mathrm{H}$ NMR and GC-MS data of product in Table 3, entry 2 
<smiles>O=CO[Si](c1ccccc1)(c1ccccc1)c1ccccc1</smiles>

CAS Registry Number: 18670-64-9; Identification data.[4]

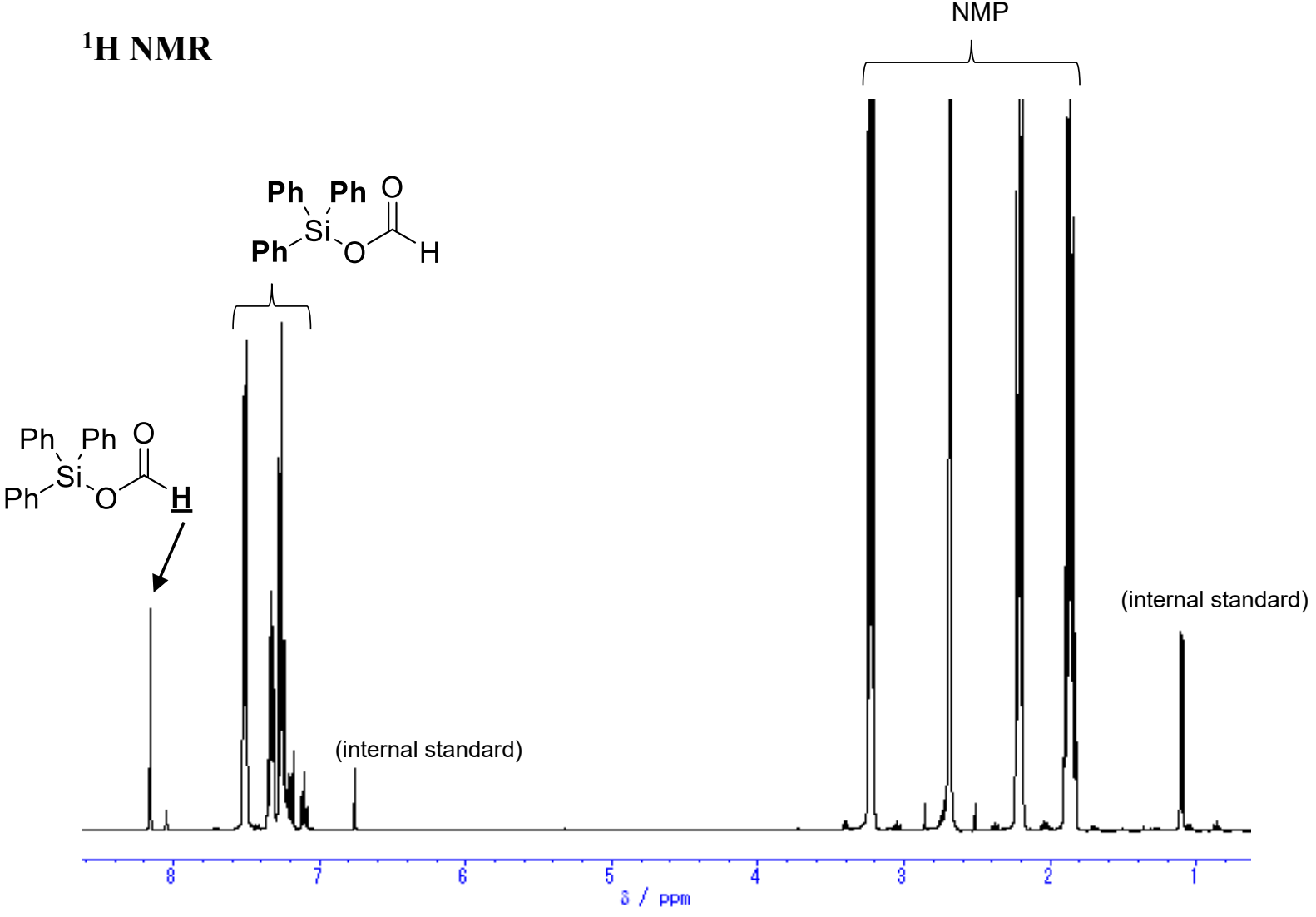

Internal standard: 1,3,5-triisopropylbenzene

\section{GC-MS}

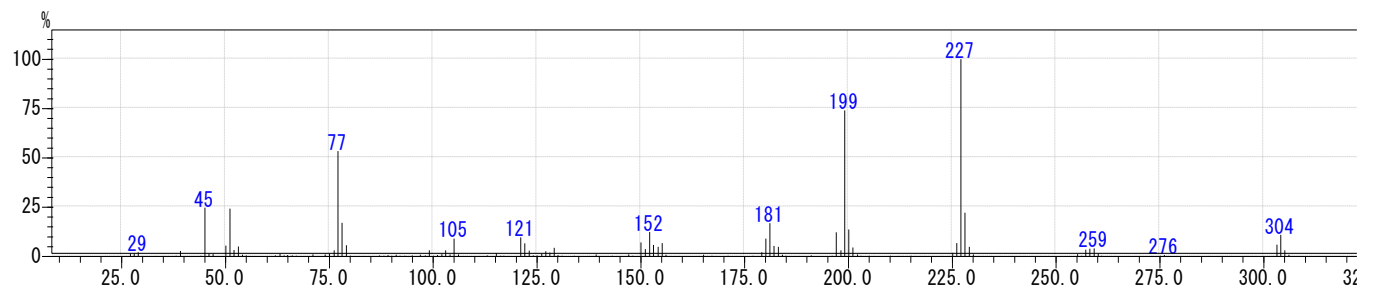

Figure S5. ${ }^{1} \mathrm{H}$ NMR and GC-MS data of product in Table 3, entry 3 
<smiles>C[Si](OC=O)(c1ccccc1)c1ccccc1</smiles>

CAS Registry Number: 287978-57-8; Identification data.[4]

\section{${ }^{1}$ H NMR}

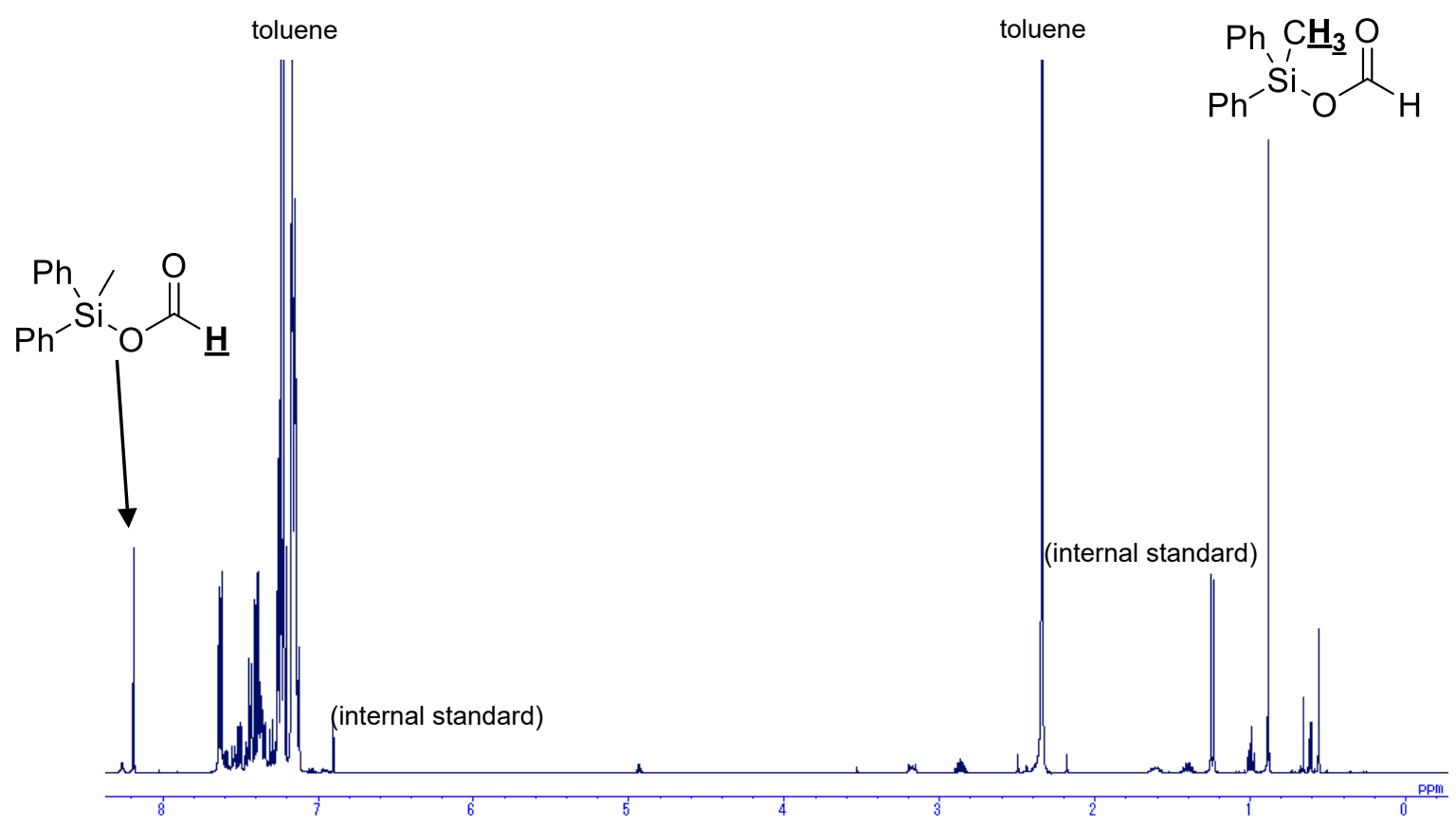

Internal standard: 1,3,5-triisopropylbenzene

\section{GC-MS}

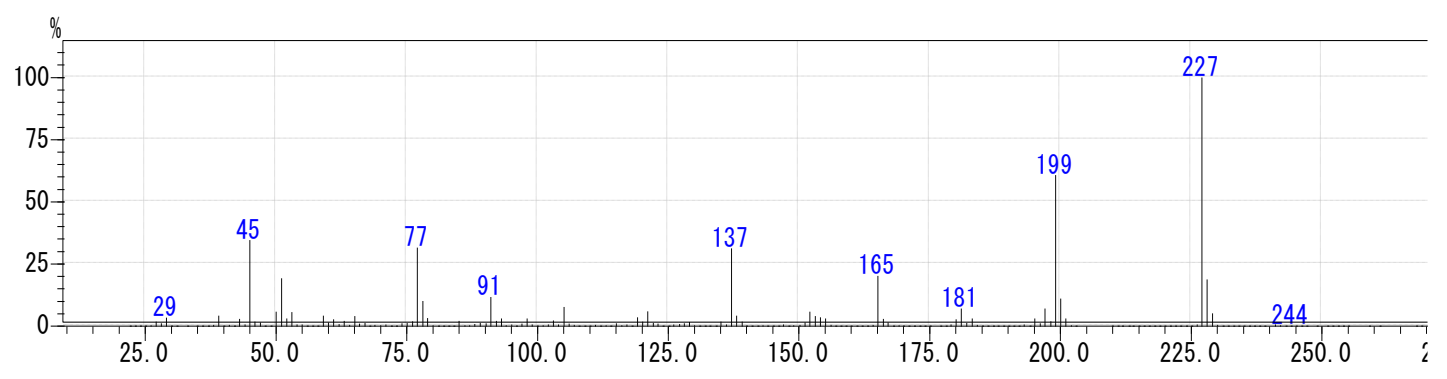

Figure S6. ${ }^{1} \mathrm{H}$ NMR and GC-MS data of product in Table 3, entry 4 
<smiles>CCO[Si](OC=O)(OCC)OCC</smiles>

Identification data.[5]

\section{${ }^{1}$ H NMR}<smiles>CCO[SiH2]O</smiles>

EtO<smiles>CCO[Si]C=O</smiles>

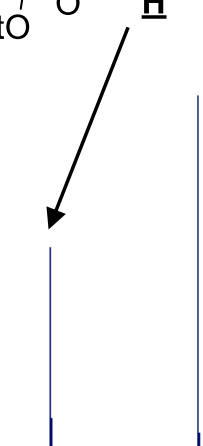

(internal standard)<smiles>CCO[AlH2]OCC</smiles>

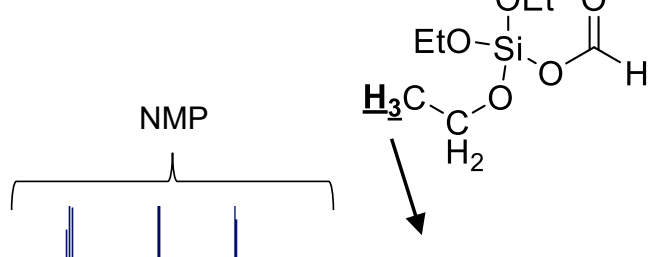

Internal standard: 1,3,5-triisopropylbenzene

\section{GC-MS}

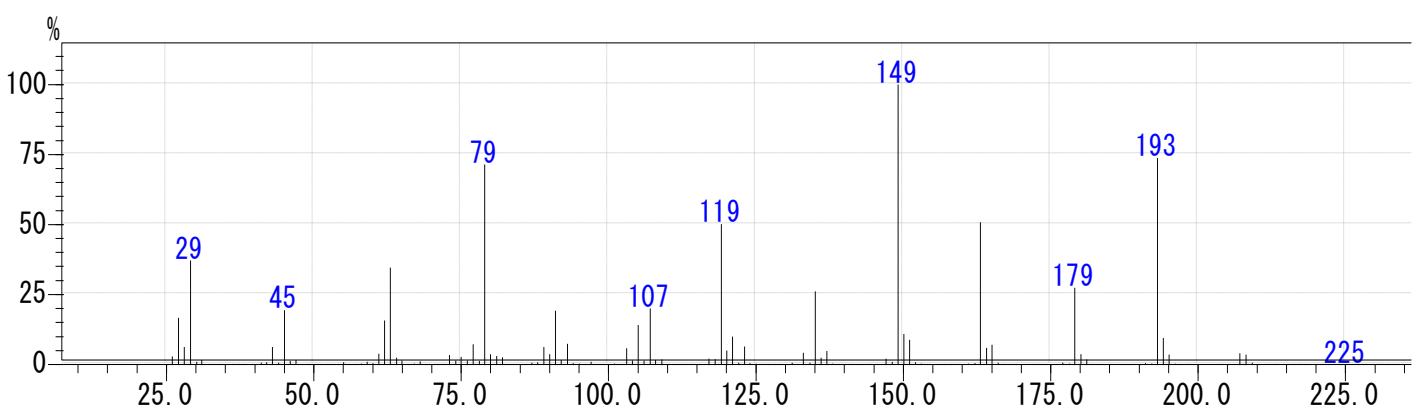

Figure S7. ${ }^{1} \mathrm{H}$ NMR and GC-MS data of product in Table 3, entry 5 
$\mathrm{Me}_{2} \mathrm{HSi}-\mathrm{O}-\mathrm{SiHMe}_{2}$<smiles>O=CO[Si]</smiles>

$\mathrm{Si}=\mathrm{SiMe}_{2}-\mathrm{O}-\mathrm{SiMe}_{2} \mathrm{OC}(\mathrm{O}) \mathrm{H}$, etc.

\section{${ }^{1}$ H NMR}
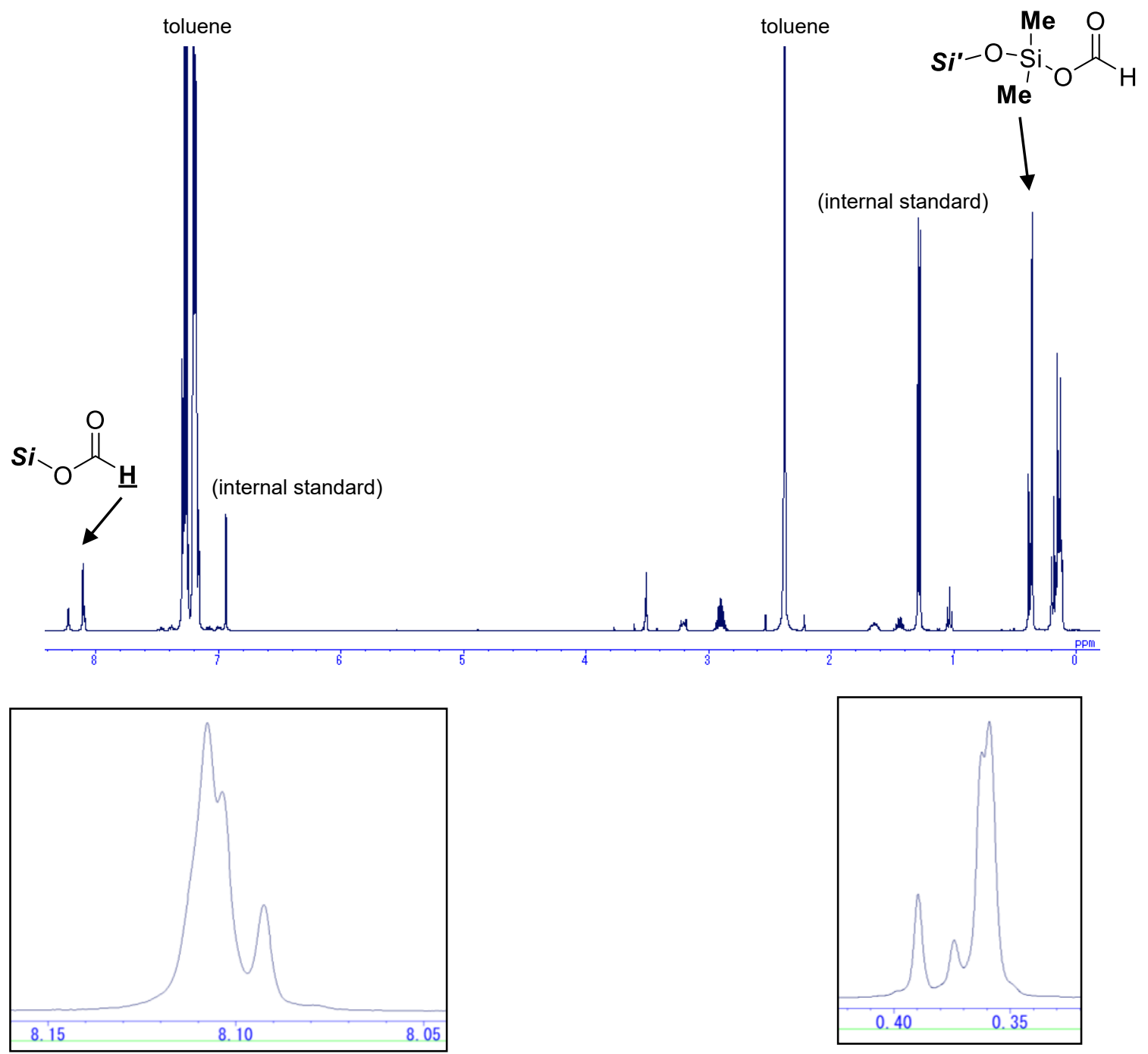

Internal standard: 1,3,5-triisopropylbenzene

Figure S8. ${ }^{1} \mathrm{H}$ NMR spectrum of product in Table 3, entry 6 


\section{References}

[1] K. Martin, J. Nõges, K. Haav, S. A. Kadam, A. Pung, I. Leito, Eur. J. Org. Chem., 2017, 5231-5237.

[2] A. Jansen, H. Görls, S. Pitter, Organometallics, 2000, 19, 135-138

[3] J. Koo, S. H. Kim, S. H. Hong, Chem. Commun. 2018, 54, 4995-4998.

[4] S. Itagaki, K. Yamaguchi, N. Mizuno, J. Mol. Catal. 2013, 366, 347-352.

[5] X.-F. Liu, R. Ma, C. Qiao, H. Cao, L.-N. He, Chem. Eur. J. 2016, 22, 16489-16493.

[6] K. Motokura, M. Naijo, S. Yamaguchi, A. Miyaji and T. Baba, Chem. Lett., 2015, 44, $1217-1219$.

[7] M. Hulla, G. Laurenczy, P. J. Dyson, ACS Catal. 2018, 8, 10619-10630. 